\title{
Challenges and Opportunities for promoting Maternal, New born, and Child Health in urban informal settlements: perspectives of Community Health Volunteers in Nairobi, Kenya
}

\author{
Jane Osindo', Pauline Bakibinga ${ }^{1}$, Nicholas Ngomi', Eva Kamande ${ }^{1}$, Peterrock Muriuki ${ }^{1}$, \& \\ Catherine Kyobutungi ${ }^{1}$ \\ 1 Health Challenges and Systems Program, \\ African Population and Health Research Center
}

Jane.osindo@gmail.com

\begin{abstract}
Across the world, Community Health Volunteers ( $\mathrm{CHVs})$ are recognised as first line health care providers. Overtime, the Kenyan government has acknowledged CHVs as an integral component in provision of first line health care services at the community level. This paper uses data from four group discussions with $\mathrm{CHVs}$ and two key informant interviews with sub-County Community Strategy Coordinators to examine the lived experiences of CHVs. The findings show that meaningful engagement of CHVs is hampered by lack of logistical support, recognition, insecurity, and inadequate resources. Despite the bottlenecks, voluntarism is their greatest driving force. They noted that their work could be enhanced through logistical support from the government involving training, provision of equipment, remuneration and recognition in the community. The findings suggest that there is need for close coordination between the national government and the community units for $\mathrm{CHVs}$ to contribute to improved health outcomes at the local level.
\end{abstract}

Key words: Community Health Volunteers, Maternal and Child Health, Urban Informal Settlements, Kenya

\section{Résumé}

Les volontaires de santé communautaire (VSC) sont reconnus comme des fournisseurs de soins de santé de première ligne à travers le monde. Au Kenya, avec le temps, le gouvernement a reconnu les VSC comme partie intégrante de l'offre de soins de santé communautaire de première ligne. Cet article utilise les données de quatre discussions de groupe avec des VSC et deux entretiens avec des informateurs-clés avec les coordonnateurs de la stratégie communautaire au niveau du sous-canton en vue d'examiner les expériences vécues de VSC. Les résultats ont montré que l'engagement significatif du VSC est entravé par le manque de soutien logistique, de reconnaissance, de même que l'insécurité et l'insuffisance des ressources. Malgré les goulets d'étranglement, le volontariat est leur plus grande force motrice. Les VSC ont noté que leur travail pourrait être amélioré grâce à l'appui logistique du gouvernement par la formation, la fourniture d'équipements, la rémunération et la reconnaissance dans la communauté. Les résultats suggèrent la nécessité d'une étroite coordination entre le gouvernement national et les unités communautaire pour que les VSC puissent effectivement contribuer à améliorer la santé au niveau local.

Mots clés: Les volontaires de santé communautaires, santé maternelle et infantile, Taudis urbain, Kenya

\section{Introduction}

The global shortage of Human Resources for Health $(\mathrm{HRH})$ and the need to ensure universal health coverage worldwide resulted in the engagement of Community Health Volunteers (CHVs) as an alternative workforce (WHO, 2007). This was seen as a critical component in mitigating the $\mathrm{HRH}$ crisis at national and community levels. $\mathrm{CHVs}$ were identified as a distinguishing feature of providing primary

health care for individuals in resource poor settings in the 1978 Alma-Ata Declaration (Lehmann and Sanders, 2007). Kenya, like many other countries in $\mathrm{CHVs}$ as the first line of health service providers and linked them to primary health facilities under supervision of Community Health Extension Workers (CHEWs) (GOK, 2005, Randall R. Bovbjerg et al., 20I4). The contributions of CHVs to primary health 
care is increasingly gaining recognition in various areas in Kenya as is the case worldwide (Haines et al., 2007).

Task shifting, described as a review and subsequent delegation of tasks to the lowest category that can perform them successfully, has been well received in Kenya as a community strategy (Mumbo et al., 2013, Samb et al., 2007). A study conducted in Busia County between 2008 to 2010 showed that the community health strategy is an appropriate platform to deliver community based interventions (Wangalwa et al., 2012). A review of literature shows consensus on some underlying issues regarding $\mathrm{CHVs}$ (Christopher et al., 20II); they are valuable to communities through their services which aim to improve coverage and access to basic health care, they are reliable because they are conveniently located within the same geographical area of the populations they serve, and are available when facilities are closed (Kelly et al., 200I, Gilmore and McAuliffe, 2013). Most importantly, they work on the front lines of medical care mainly helping people in disadvantaged communities (Randall R. Bovbjerg et al., 20।4).

Despite the efforts to mitigate the $\mathrm{HRH}$ crisis by using $\mathrm{CHVs}$, Kenya is still faced with escalating risks of poor health outcomes. This is partly due to the persistent shortage of health care specialists, which is compounded by the scarcity and uneven distribution of available government health facilities (Adano, 2008, Fosu, 1989, Kinfu et al., 2009). This is the scenario more so in poor resource settings like the urban informal settlements in Kenya which are hard hit as a result of the high population density competing with low health resource allocation. Kenya, like most of sub-Saharan Africa is urbanizing rapidly, where approximately $60 \%$ of urban residents live in slums (UN Habitat, 2007, UN Habitat, 20I0). This rapid urbanization has not been matched with the expansion of health service delivery leading to poor quality of maternal and child care services among the urban poor. While there are individual and community level barriers to accessing and using health care services in the slums, the poor state of both maternal (Tawiah, 20II) and child care services contributes to high under- five and maternal mortality (Emina et al., 20I I). As a result, the urban poor in Kenya exhibit poor child, neonatal and maternal health indicators including high levels of maternal mortality $(706 / 100,000$ compared to $488 / 100,000$ the national average) and, high infant and under-five mortality (Fotso et al., 2009, Ziraba et al., 2009a, Ziraba et al., 2009b). Challenges have been experienced in the implementation of the community heath strategy in these areas due to the imbalanced socio-economic aspects of the communities and inadequate service delivery structure (Patel and Burke, 2009). This denies CHVs the opportunity to adequately provide community based health services. The failure to entirely integrate $\mathrm{CHVs}$ in national policies has left the existing community strategy structures struggling to stay abreast of community health service delivery (Rosato et al., 2008). The CHVs however continue working as volunteers and strive to effectively serve the community members within their coverage areas.

Whereas the CHVs in informal settlements in Kenya actively participate in community based interventions coordinated by the government, their impact is not in the public domain. This is because very little is documented regarding their participation and contributions to health care delivery. This paper contributes to existing knowledge regarding the roles of $\mathrm{CHVs}$ by describing their experiences specifically with respect to promotion of Maternal, Newborn and Child Health $(\mathrm{MNCH})$ services in urban informal settlements. Information was sought from the $\mathrm{CHVs}$ working in Korogocho and Viwandani slums to identify challenges and opportunities for promoting $\mathrm{MNCH}$ in this setting.

\section{Methods \\ Study design}

The paper is based on baseline survey data collected as part of a larger intervention project implemented by the African Population and Health Research Center (APHRC). The project-also known as Partnership for Maternal, Newborn and Child Health (PAMANECH)-was designed and rolled out in July 2012 by APHRC in Korogocho and Viwandani slums of Nairobi, Kenya with a broader aim of strengthening the health care delivery system in the urban informal settlements to be more responsive to the health care needs of mothers and their children (Bakibinga et al., 20l4). As part of the intervention $\mathrm{CHVs}$ were recruited, trained and linked to work with private and public health care providers. Part of the baseline survey utilized information sought from the CHVs working in the two slums in order to identify challenges and opportunities for promoting $\mathrm{MNCH}$ services in these settings.

\section{Study Setting}

The study utilized an exploratory qualitative design to provide a description of CHVs' lived experiences in Korogocho and Viwandani slums of Nairobi where APHRC has been running the Nairobi Urban Health and Demographic surveillance System (NUHDSS) since 2002. These slums are about seven kilometers apart and are unique in their demographic characteristics (Emina et al., 20I I). The health risks and challenges resulting from limited access to 
healthcare for children and adults in the two informal settlements are more or less similar (Fotso et al., 2008).

\section{Participants and Data Collection}

Six field interviewers were recruited based on academic qualification, fluency in English and Kiswahili, and previous experience in conducting qualitative surveys. The interviewers were trained on the study design and qualitative interview techniques. They also reviewed the interview guide, and held mock interviews during the training. Data were collected through four Focus Group Discussions (FGDs) and two Key Informant Interviews (KIls). With the help of the trained field interviewers, CHVs residing and working in the two communities were recruited to take part in the FGDs which were conducted in October 2013. The CHVs selected were those that were actively participating in community work under the sub-county community health strategy. Each group had 10 to 15 participants who were selected to ensure that different areas in the slums were represented. The FGDs had mixed representation of the different sexes as there was no anticipated personal information that would be discussed in the presence of the opposite sex. Key Informant Interviews (KIls) were conducted with the sub-County Community Strategy Coordinators in February 20I4. On average, the FGDs lasted I hour and the KIls 2 hours. All interviews were audio recorded and later transcribed and translated into English by an experienced transcriber. The participants differed in their age, level of education, years they had worked as CHVs in the communities, and activities they were involved in. Table I summarizes some of the background characteristics of the participants.

TABLE I

Distribution of FGD participants by select background characteristics

\begin{tabular}{llll}
\hline Characteristic & Description & Total $(\mathbf{n}=48)$ & $\%$ \\
\hline Slum of residence & Viwandani & $2 \mid$ & 44.0 \\
\hline & Korogocho & 27 & 56.0 \\
\hline Age & $18-24$ & 3 & 6.2 \\
\hline & $25-44$ & 32 & 66.7 \\
\hline & $45-64$ & 12 & 25.0 \\
\hline & $65+$ & 1 & 2.1 \\
\hline Sex & Male & 29.2 \\
\hline & Female & 14 & 70.8 \\
\hline Level of education & Primary & 34 & 37.5 \\
\hline & Secondary & 18 & 58.3 \\
\hline & Higher & 28 & 4.2 \\
\hline Duration worked as a CHV & I-I0 years & 2 & 66.7 \\
\hline & Over I0 years & 16 & 33.3 \\
\hline
\end{tabular}

A thematic interview was designed, reviewed by a team of experts in $\mathrm{MNCH}$, pretested and used by the research team to guide the interviews. The guide was translated into Kiswahili and back-translated into English by an independent translator to ensure that meaning was not lost in the process. The discussions were also held in Kiswahili, which is the national language spoken widely in Kenya and well understood by all participants. The discussions were held in community halls and each discussion had a moderator and a note taker.

\section{Ethical Considerations}

Ethical clearance was granted both internally by APHRC review board and externally by the Kenya Medical Research Institute's (KEMRI) Scientific and Ethics Review Unit (SERU) approval No. 393. Informed consent was sought from all study participants and contact details of the research team, and KEMRI's SERU were provided for any clarifications. To ensure confidentiality, participants who consented to participate in the study were given numbered tags for identification as opposed to using their actual names during the discussions. Permission 
to record the discussions was also sought from all participants.

\section{Data analysis}

The transcribed discussions were divided into three themes: Roles of CHVs, Challenges faced by $\mathrm{CHVs}$ while executing their duties and Opportunities for improving CHVs roles, as predefined in the thematic discussion guide. Under each theme, the unit of analysis was the specific text about the CHVs' responses in relation to a particular subject. The discussion notes were further supported by observational notes of each FGD. The analysis which focused on main areas of consensus and disagreement was conducted using a thematic approach. In the first instance a process of initial reading and re-reading of the transcripts while listening to the audio recordings was done to make a sense of the data. A preliminary coding scheme was then developed based on themes from the discussion guide. This was followed by manual content analysis informed by Graneheim and Lundman (2004) in order to describe and interpret the experiences of the CHVs'. Open coding was followed by scrutiny of each code resulting in refinement of the coding scheme. The resultant codes were organized under key themes. Findings from the $\mathrm{CHVs}$ were triangulated with key informant interview data from the community strategy coordinators for Makadara and Kasarani sub counties where the CHVs work.

We employed several strategies in order to enhance credibility of the study's findings as suggested by Creswell and Miller (2000). The thematic discussion guide used during the FGDs allowed for a degree of consistency throughout the discussions. The guide was pilot-tested with 22 $\mathrm{CHVs}$. Clarifications were sought from the participants during the interview process by the moderator paraphrasing points that required explanation. During the analytical process, discussions amongst the co-authors were undertaken to ensure a common understanding of the data and interpretation of emergent themes (Graneheim and Lundman, 2004).

\section{Results}

Table 2 represents the type, distribution, and content of the interviews that were conducted in the two slum communities.

Table 2

Group Composition and Discussion Guide for the Focus Group Discussions and Key Informant Interviews

\begin{tabular}{|c|c|c|c|c|}
\hline \multirow[t]{2}{*}{ Participants } & \multirow{2}{*}{$\begin{array}{l}\text { Type of } \\
\text { interview }\end{array}$} & \multicolumn{2}{|c|}{ Number of participants } & \multirow[t]{2}{*}{ Issues discussed/ discussion guide } \\
\hline & & Korogocho & Viwandani & \\
\hline $\begin{array}{l}\text { Community } \\
\text { Health } \\
\text { Volunteers }\end{array}$ & $\begin{array}{l}\text { FGD } \\
\text { FGD }\end{array}$ & $\begin{array}{l}15 \\
12\end{array}$ & $\begin{array}{l}11 \\
10\end{array}$ & \multirow{2}{*}{$\begin{array}{l}\text { - Community health } \\
\text { system/Referral patterns } \\
\text { Knowledge, attitudes and } \\
\text { practices regarding breastfeeding } \\
\text { - Immunization and health care } \\
\text { seeking behavior } \\
\text { - Family planning }\end{array}$} \\
\hline $\begin{array}{l}\text { Sub-County } \\
\text { Community } \\
\text { Strategy } \\
\text { Coordinators }\end{array}$ & KII & I & I & \\
\hline
\end{tabular}

\section{Roles of the CHVs}

There is a consensus on the role of CHVs. They perceive and describe themselves as health volunteers and are viewed by the sub-County Community Strategy Coordinators (SCCSCs) as such. Their roles mainly involve the following:

\section{Community Health Advisors and Educators}

They offer advice on family planning, exclusive breastfeeding, proper hygiene and general health. On matters pertaining to $\mathrm{MNCH}$, they advise and encourage mothers to seek antenatal care (ANC) and postnatal care (PNC) services. In a community where some women still seek care from traditional birth attendants, the $\mathrm{CHVs}$ advise and counsel women to seek skilled care from health facilities.

This was highlighted by a $\mathrm{CHV}$ who said,

'Our role is to advise the women who rely on Traditional Birth Attendants (TBAs); so we counsel them to go to the clinic...' (FGD Korogocho).

As health educators they give health related information and counsel the community members according to their health needs. One of them referred to education as a critical need in the community by saying:

'People in the community need counseling or education...this woman who is pregnant should be 
educated on the foods she's supposed to take.' (FGD Viwandani).

They are occasionally called upon to give health talks to clients in the health facilities on days that have been set aside for special clinics. The health talks are based on nutrition, ANC and PNC services. This was further emphasised as follows:

'They offer all services like once they go for ANC they give them health talks, then when they go to the room (waiting bay) they give them advice on various issues, family planning, clinic attendance, when to return and how to take care of themselves.' (KII Korogocho).

\section{Health Workers and Community Mobilizers}

While visiting clients in their houses, they provide home-based care services such as supporting and caring for the sick, assist mothers to care for newborns and refer others to health facilities when need arises. They also make follow up visits to offer continuous care to clients that were referred. As community mobilizers, they create demand for health services by sensitizing community members on services offered during health related activities like medical camps and outreaches. During such activities they distribute family planning commodities, vaccinate children during the polio eradication campaigns and mobilise community members to attend the health drives in the community.

\section{Link between community and health facilities}

They serve as a link between the community and health facilities. They enlighten community members about existing primary health care facilities and services offered. They also monitor health indicators and outcomes in the community and inform the facilities on the health status of the communities. They refer to themselves as the

'...first service providers in the community'. (FGD Viwandani).

\section{Challenges faced by $\mathrm{CHVs}$ while executing their duties}

The $\mathrm{CHVs}$ expressed concerns in relation to various challenges they face that are a setback in their efforts to provide services to the community. The views raised were categorized as follows:

\section{Rising insecurity and lack of emergency transport services}

There are high levels of insecurity experienced by $\mathrm{CHVs}$ in both communities. It is more risky during the night hindering free movement of the $\mathrm{CHVs}$ and their clients during emergencies. This was pointed out in the discussions as follows: '...the other problem these mothers get is insecurity when they are delivering at night. We live in the ghetto (slum) and when you come out at night you find young boys on the streets mugging people. So when you meet them they will definitely harm you and other people fear to come out because they will be harmed before they even reach this woman to give her help and so the woman ends up giving birth at home with all the risks mentioned before'. (FGD Korogocho).

On the other hand, ambulance services are not readily available in the communities and transportation of clients in critical conditions to various health facilities is difficult. Poverty amongst community members also forces $\mathrm{CHVs}$ to use their own money to cater for transport and treatment costs for some clients. Talking about lack of transportation, a CHV said,

'We don't have an emergency ambulance in our area; because sometimes we find patients in very critical conditions; we also don't have motorbikes to ferry the patients.' (FGD Viwandani).

On lack of money by the client, another $\mathrm{CHV}$ said,

'Also sometimes you are called to take a patient who is bed ridden maybe on a Sunday and in that house there is no money so when the people who have called you hear they need to contribute they run away, yet there is no money for transport so you are forced to use your money since the people assume you are paid by the government to do this work.' (FGD Korogocho).

\section{Lack of commodities and resources}

Service delivery by $\mathrm{CHVs}$ largely involves physical contact with clients hence the need for essential commodities like dust aprons and latex gloves. The supply of commodities for CHVs is sporadic exposing them to health risks as they sometimes work with none. One of the respondents explained it by saying,

'...when we are doing the home based care you find that we do not have gloves you find that you want to offer the services but since I am also a human being I cannot risk my health because of someone'(FGD Korogocho).

The CHVs mentioned poor or lack of remuneration as a major barrier to their efforts to reach out to the communities as effectively as they should. One participant put it as follows:

'...if someone wants to motivate us they should consider that we also have challenges that the other people face... we would like to really do a good job but we do not have the money to do that job.' (FGD Korogocho).

Such sentiments were also expressed by key informants. One key informant noted, 
'...nobody is paying, nobody is giving them motivation and that is one challenge that limits them to the number of days that they work.' (KII Viwandani).

Throughout the discussions, it was evident that lack of resources and commodities negatively impacts on service delivery.

\section{Recognition and acceptance}

Lack of trust and/or total rejection by some community members and discrimination by link facilities discourage the $\mathrm{CHVs}$ to work well as one participant explained,

'Another challenge is that they (community members) think that $\mathrm{CHVs}$ benefit at the expense of the people of the community, so some of them do not even want to see us' (FGD Viwandani).

Expressions from the $\mathrm{CHVs}$ also indicated that they were not recognized though their work is important. They felt that the government seldom involves them in making decisions affecting their work because they are less educated.

\section{Opportunities for improving $\mathrm{CHV}$ roles}

Despite the problems faced, the $\mathrm{CHVs}$ had suggestions on how problems they face can be addressed to improve their services.

Improve security and provision of logistical support

The CHVs want insecurity to be addressed to protect them and their clients from physical and emotional harm .As a result, the clients will have access to health care when required and $\mathrm{CHVs}$ will work in a safe environment. Irrespective of the level or location of operation by any health worker, laid down precautions while handling clients need to be observed. Providing commodities necessary for giving services in a hygienic manner is an assurance of safety on their part. Availing reliable cost effective emergency transport services will increase the number of clients that can access services during emergencies. In addition, they require capacity building through refresher trainings and practice which they believe will strengthen their skills and help them perform better.

\section{Remuneration and expanded workforce}

They feel they should be considered for remuneration because they too have economic demands just like any other individual. Without a pay, they have to look for alternative sources of income to meet their needs which may affect the services they provide to the community. In addition, consideration for remuneration will make them be recognized by the government and they will get necessary support from community members. Their efforts will thus be appreciated which will boost their morale to work. One of them explained it as follows,

'The other thing is that the government should recognize that we are their eyes in the community. Then they should put us in the payroll even if we are not educated.' (FGD Korogocho).

Moreover, they expressed the need for their workforce to be increased to mitigate against natural attrition for better coverage in all sections of the community. They were positive that they would adequately penetrate their communities if the allocation of households to be visited per $\mathrm{CHV}$ is reduced.

\section{Discussion}

This paper described the lived experiences of $\mathrm{CHVs}$ regarding their roles in promoting $\mathrm{MNCH}$ in urban informal settlements. It is evident that the $\mathrm{CHVs}$ play a critical role in making healthcare accessible to the residents within the communities they serve. The $\mathrm{CHVs}$ act as a link between the health facilities and the community, bridge the gap created by insufficient human resources for health, and closely monitor health indicators and outcomes at the community level. Their roles are consistent with recommendations by the World Health Organization that emphasise the adoption of task shifting as a strategy to strengthen human resources for health alongside efforts to increase the number of trained health care workers (World Health Organization PEPFAR-UNAIDS, 2008). They engage in a variety of health care activities that largely consist of health promotion and community development activities (Lehmann and Sanders, 2007, Bhattacharyya et al., 200I, Bovbjerg et al., 20I4, Haines et al., 2007) .Their services are purely voluntary, which they are aware of. As a result, issues that affect them rarely come to the limelight of public health structures.

The demand for support from $\mathrm{CHVs}$ continues to rise but issues surrounding their ability to provide services have not been adequately addressed. They are faced with social, economic, logistical and organizational challenges in the course of their work. For instance, a study conducted among CHVs in Saradidi in Siaya County of Kenya found that poor infrastructure, weak health systems and lack of remuneration were major impediments to their work (Kaseje et al., 1987). Another study in Malawi found that $\mathrm{CHVs}$ lacked vital health information needed to appropriately carry out their work (Campbella et al., 2014). The findings of this paper show that besides the challenges identified in the existing literature, insecurity in the slums greatly hampers the work of $\mathrm{CHVs}$ in this community. Recurring incidences of mugging with high risk of physical harm is the norm 
in the slums. The situation becomes worse during the night making it difficult for the CHVs to work optimally during this time. This reduces the chances that the $\mathrm{CHVs}$ provide services in a timely manner irrespective of the urgency of their services.

Lack of sufficient recognition from the government and the community in general adversely affects the contributions of CHVs. The CHVs expressed their disappointment at the level of recognition accorded to them as they felt their efforts can only be recognized if people they work for appreciate them. They felt that the government has not done enough to give a clear direction regarding their plight as health care workers at the community, yet they make important contributions towards improving health outcomes at the local level. At the same time, some community members have reservations regarding their work which is fuelled by lack of recognition by the relevant authorities. The $\mathrm{CHVs}$ end up demoralised and their performance remains low. This translates to possible superficial service delivery putting the health of the community members served at a risk.

Community healthcare delivery requires that $\mathrm{CHVs}$ have adequate commodities and receive appropriate training in their area of work. The findings of this paper show that they rarely get logistical support from the government. Scarce supply of commodities contributes to the declining performance of their duties as they are forced to take care of their own welfare. Simple procedures in first aid will not be performed due to lack of items like cotton, gloves and iodine until one reaches a health facility. The interval between the occurrence of a health event and receiving first aid is long enough to worsen the outcome. They are often less educated compared to other health workers and require capacity building to strengthen their capabilities in discharging their duties. Training opportunities are scarce and most of the time they depend on training from non-governmental entities. Trainings are important for the CHVs to stay abreast of the current health issues facing communities and how they can be handled. They will often lag behind in attaining new knowledge involving health matters within their mandate. This negatively impacts on their services in the community as they continue applying service delivery skills that may be outdated.

Despite the unfavourable nature of the environment they work in, the CHVs are optimistic their performance can be greatly improved largely through the participation of government and communities. The $\mathrm{CHVs}$ look forward to the government fully integrating them into the formal health sector. This would provide an opportunity for the government to address the challenges they face and for the community to recognize their work.

Institutional and community response towards engagement of $\mathrm{CHVs}$ is key to enhancing their capacity to provide services. Increasing synergy between the health sector, the community and the $\mathrm{CHVs}$ may improve the way they function and full integration into the health system will make them more responsible for their activities. Security in the communities may be enhanced through strengthening the existing community policing system and involving community members that volunteer to offer security services within their own villages. Continuous sensitization regarding the roles of the $\mathrm{CHVs}$ in the communities may increase community member's awareness and solidify their'

status as health care providers in the community.

\section{Conclusion}

The study showed that the CHVs play critical roles in ensuring the communities they serve have adequate access to health care. The findings further showed that possible strategies for enhancing the capacity of $\mathrm{CHVs}$ to effectively provide services may strengthen their capability as they supplement the existing human resource for health outfit at the grassroots. Appropriate measures if taken to address the issues may positively change the current situation. A possible limitation identified was that the interviews were conducted in Kiswahili and translated into English. There is no doubt that important elements of nuance in the raw data may be lost in the translation process. Further, the community health volunteers in the study were recruited from an urban setting, and their views and experiences may therefore not be representative of CHVs in other settings such as non-slum and rural areas.

\section{Authors' contributions}

JO managed the literature searches, analysed the qualitative data and contributed to the first draft of the manuscript. PB contributed to the literature searches and drafting of the first manuscript. JO, PB, NN, EK \& PM participated in the data collection exercise. CK contributed to the design of the study and writing the manuscript. All the authors reviewed and approved of the final manuscript.

\section{Interests}

None declared

\section{Acknowledgements}

PAMANECH is funded by Comic Relief UK. The funder was not involved in the decision to develop and publish this manuscript. We are also grateful to 
the core funding to APHRC by SIDA and the Hewlett Foundation.

\section{References}

Adano, U. 2008. The health worker recruitment and deployment process in Kenya: an emergency hiring program. Hum Resour Health, 6, 14784491.

Bakibinga, P., Ettarh R., Ziraba, A.K., Kyobutungi, C., Kamande, E., Ngomi, N., and Osindo, J. 2014. The effect of enhanced public- private partnerships on Maternal, Newborn and child Health Services and outcomes in Nairobi-Kenya: the PAMANECH quasi-experimental research protocol. BMJ Open.

Bhattacharyya, K., Winch, P., Leban, K. and Tien, M. 200I. Community Health Worker Incentives and Disincentives: How They Affect Motivation, Retention, and Sustainability. Basic Support for Institutionalizing Child Survival Project (BASICS II) for the United States Agency for International Development.

Bovbjerg, R.R., Eyster, L., Ormond,B.A., Anderson, T., and Richardson, E. 20l4. Integrating Community Health Workers into a Reformed Health Care System. Urban Institute.

Campbella, N., Schifferb,E., Buxbaumc, A., Mcleand, E., Perryc, C., and Sullivane, T. M. 20I4. Taking knowledge for health the extra mile: participatory evaluation of a mobile phone intervention for community health workers in Malawi Global health sci \& pract.

Christopher, J. B., Le May, A., Lewin, S. and Ross, D. A. 20II. Thirty years after Alma-Ata: a systematic review of the impact of community health workers delivering curative interventions against malaria, pneumonia and diarrhoea on child mortality and morbidity in sub-Saharan Africa. Hum Resour Health, 9, 1478-449I.

Creswell, J. W. and Miller, D. L. 2000. Determining validity in qualitative inquiry. Theory into practice, 39, I24-I 30.

Emina, J., Beguy, D., Zulu, E. M., Ezeh, A. C., Muindi, K., Elung'ata, P., Otsola, J. K. and Yé, Y. 20II. Monitoring of health and demographic outcomes in poor urban settlements: evidence from the nairobi Urban Health and Demographic Surveillance System. Journal of Urban Health, 88, 200-218.

Fosu, G. B. 1989. Access to health care in urban areas of developing societies. / Health Soc Behav, 30, 398-4II.

Fotso, J. C., Ezeh, A., Madise, N., Ziraba, A. and Ogollah, R. 2009. What does access to maternal care mean among the urban poor? Factors associated with use of appropriate maternal health services in the slum settlements of Nairobi, Kenya. Maternal and child health journal, I3, I30137.

Fotso, J., Ezeh, A. and Oronje, R. 2008. Provision and Use of Maternal Health Services among Urban Poor Women in Kenya: What Do We Know and What Can We Do? Journal of Urban Health, 85, 428-442.

Gilmore, B. and Mcauliffe, E. 2013. Effectiveness of community health workers delivering preventive interventions for maternal and child health in lowand middle-income countries: a systematic review. BMC public health, I3, I-I4.

GOK 2005. Reversing the trends; The second National Health Sector Strategic Plan of Kenya. Taking the kenya Essential Package for Health to the Community; A strategy for the delivery of level one services. Nairobi, Kenya: Government of Kenya.

Graneheim, U. H. and Lundman, B. 2004. Qualitative content analysis in nursing research: concepts, procedures and measures to achieve trustworthiness. Nurse education today, 24, 105II 2.

Haines, A., Sanders, D., Lehmann, U., Rowe, A. K., Lawn, J. E., Jan, S., Walker, D. G. and Bhutta, Z. 2007. Achieving child survival goals: potential contribution of community health workers. The Lancet, 369, 2I $21-213 \mid$.

Kaseje, D. C., Spencer, H. C. and Sempebwa, E. K. 1987. Characteristics and functions of community health workers in Saradidi, Kenya. Ann Trop Med Parasitol, I, 56-66.

Kelly, J. M., Osamba, B., Garg, R. M., HameL, M. J., Lewis, J. J., Rowe, S. Y., Rowe, A. K. and Deming, M. S. 200I. Community health worker performance in the management of multiple childhood illnesses: Siaya District, Kenya, 1997200I. American journal of public health, 91, I6I71624.

Kinfu, Y., Dal Poz, M. R., Mercer, H. and Evans, D. B. 2009. The health worker shortage in Africa: are enough physicians and nurses being trained? Bull World Health Organ, 87, 225-30.

Lehmann, U. and Sanders, D. 2007. Community Health Workers: What do we know about them? The state of evidence on programmes, activities, costs and impact on health outcomes of using community health workers. WHO.

Mumbo, H. M., Ochieng, B. M., Kaseje, D. O., Aila, F. O., Odera, O. and Ayugi, M. E. 2013. Uptake of task shifting as a community strategy in Kenya. European Scientific Journal, 9.

Naicker, S., Plange-Rhule, J., Tutt, R. C. and Eastwood, J. B. 2009. Shortage of healthcare 
workers in developing countries--Africa. Ethnicity \& disease, 19, 60.

Patel, R. B. and Burke, T. F. 2009. Urbanization An Emerging Humanitarian Disaster. New England Journal of Medicine, 36I, 74I-743.

Rosato, M., Laverack, G., Grabman, L. H., Tripathy, P., Nair, N., Mwansambo, C., Azad, K., Morrison, J., Bhutta, Z., Perry, H., Rifkin, S. and Costello, A. 2008. Community participation: lessons for maternal, newborn, and child health. Lancet, 372, 962-7I.

Samb, B., Celletti, F., Holloway, J., Van Damme, W., De Cock, K. M. and Dybul, M. 2007. Rapid expansion of the health workforce in response to the HIV epidemic. N Engl J Med, 357, 25 I 0-4.

Tawiah, E. O. 20I I. Maternal health care in five subSaharan African countries. 20II, 25.

UN HABITAT 2007. Sustainable urbanization: Local actions for urban poverty reduction, emphasis on finance and planning. 2/st session of the Governance Council, 16-20.

UN HABITAT 2010. The state of African cities 2010: Governance, inequality and urban land markets. United Nations Human Settlements Programme (UN-HABITAT) Nairobi.

Wangalwa, G., Cudjoe, B., Wamalwa, D., Machira, Y., Ofware, P., Ndirangu, M. and Ilako, F. 2012.
Effectiveness of Kenya's Community Health Strategy in delivering community-based maternal and newborn health care in Busia County, Kenya: non-randomized pre-test post test study. Pan Afr Med J, I, 26.

Wasunna, B., Zurovac, D., Goodman, C. A. and Snow, R. W. 2008. Why don't health workers prescribe ACT? A qualitative study of factors affecting the prescription of artemetherlumefantrine. Malaria Journal, 7, 29.

WHO 2007. Task shifting to tackle health worker shortage. Geneva: World Health Organization.

World Health Organization PEPFAR-UNAIDS 2008. Task shifting: rational redistribution of tasks among health workforce teams. Global recommendations and guidelines. World Health Organization, Geneva.

Ziraba, A. K., Madise, N., Mills, S., Kyobutungi, C. and Ezeh, A. 2009a. Maternal mortality in the informal settlements of Nairobi city: what do we know? Reprod Health, 6, 1742-4755.

Ziraba, A. K., Mills, S., Madise, N., Saliku, T. and Fotso, J.-C. 2009b. The state of emergency obstetric care services in Nairobi informal settlements and environs: Results from a maternity health facility survey. BMC health services research, 9, 46. 